\title{
Cultural Constraints on Literary Translation
}

\author{
Wei Lou \\ School of Foreign Languages, Qingdao University of Science and Technology \\ Qingdao 266061, China \\ E-mail: cindylw@163.com
}

\begin{abstract}
Translation is no longer considered a single, unified reproduction of the original but a kind of rewriting which reflects a certain ideology and literary norm and literary translation is no exception. This essay tends to explore the cultural constraints on literary translation.
\end{abstract}

Keywords: Cultural constraints, Literary translation

\section{Introduction}

It is commonly approved that any work of literature is nurtured by culture. The subject matter, the topic, the way the author reveals himself, are products of certain circumstances of a certain age. Since translated literature is regarded as a branch of target literary system (Xie Tianzhen, 2003:154), translated literary products share certain manifestations of certain cultural traits at a particular period of time. The role culture plays in the translation of literary texts can thus never be obliterated. In this essay, we are to have an overview of the development of translation theory and the changes in viewpoints on translation due to the recognition of cultural intervention in translation. Then, the essay discusses the relationship between culture and literary translation and finds out how culture constrains literary translation activity.

\section{The Development of Translation Theory and the Recognition of Cultural Intervention}

Roughly speaking, the development of translation theory in the Western world has undergone three stages. The first stage, known as "traditional" or "pre-scientific" period, lasted from the very beginning of Babel tower until World War II. The translation involved in this period was concerned mainly with literature, with the focus of translation theory on literary translation. The heatedly discussed issue in this period was the age-old literal versus free translation. In the middle of 20th century, some scholars with linguistics background began to study translation. They felt that translation should be studied in a "scientific" way. J.C Catford and Nida are the most prominent figures in this approach. They applied linguistic theory to translation and gained us a new insight into the old phenomenon. The development of linguistics has greatly contributed to the study of translation since translation itself is intricately related to language. In this period translation was basically understood as a process of linguistic code switching and the concept of equivalence had become the focus of translation theorists. Despite the great contribution of linguistics to translation studies, this approach seemed powerless in explaining some of the translation phenomena, especially when some cultural factors involved. Hence a few of them began to give up their attempts to make translation strictly scientific and came back to consider the cultural context in which a translation had been made. Such unscientific rationale as "it sounds better" was also considered (Gentzler, 1993: 182). Snell-Hornby named it the "cultural return" and predicated that it would be the main trend of translation study in the new century. In research, culture has been recognized as inseparable from translation for a long time. For instance, Nida used to take cultural factors into account while exploring his theory, as he said: it is true that all translating and interpreting the source and target languages must be implicitly or explicitly compared, but all such interlingual communication extends far beyond the mechanics of linguistic similarities and contrasts.... The meaning of verbal symbols on any and every level depends on the culture of the language community. Language is a part of culture, and in fact it is the most complex set of habits that any culture exhibits. Language reflects the culture, and in many respects constitutes a model of the culture (Schaffner, 1995: 1).

Actually, Nida still talked about the meaning-based translation in spite of the engagement of culture, which is rather different from the present-day theorists' perspective. However, it has gradually been recognized that to a great extent culture determines the translation process and the final version. For instance, shortly after Roman conquest of Greece, in order to introduce Greek culture into Rome, Roman translators did their translations carefully and faithfully, seeking to imitate the style of the original, which they thought was more advanced than theirs, such as Quintus Ennius' (239 
B.C.? -169B.C.) translation of Euripides' tragedy. Later on, Romans realized that they had conquered Greece, and they were victors, so the Roman translators changed their viewpoints on translation entirely. Paying scant attention to the integrity of the original, they adapted the source text at will so as to show Roman literary achievements. Translation was understood as neither an "interpretation" nor an "imitation", but a "competition" with the original.

In his book Translation, Rewriting and the Manipulation of Literary Fame, Andre Lefevere made a detailed analysis of the sociological and cultural factors that govern the translation process. He claimed that two factors basically determine the translation process, that is, the ideology and the literary norm dominant in the receptor culture at the time a translation is made.

The ideology dictates the basic strategy the translator is going to use and also dictates the selection of the content of the original. Toury found that most texts were chosen to be translated for ideological reasons (Gentzler, 1993: 126). Andre Lefevere held that on every level of the translation process, if linguistic considerations enter into conflict with considerations of an ideological and/or poetical nature, the latter consideration tends to win (Lefevere, 1990: 24)

The dominant literary norms at a given time also play a decisive role in the translation process. Andre Lefevere investigated the nineteenth century's translations of Catullus' second poem and found that most of it rhymes even if the original does not. He explained, the need to rhyme was by no means from the "structure" of the original, on the contrary, it was imposed on translators by the literary norms of their day, which in the nineteenth century held that acceptable poetry translations should make use of the strategy of meter and rhyme (Lefevere, 1992: 100).

\section{The Relationship between Culture and Literary Translation}

On the one hand, literary translation has never ceased to exert influence on the development of certain culture. Translation is a means of cultural enrichment and so is literary translation. Literary works, rich in cultural elements, are reflections and sublimation of society and life. Most people get an understanding of other peoples and other nations through translated texts, of which literary translation has never occupied a small proportion (Gu Jun, 2001:414). It can be said that, at the time when a nation witnesses a considerable importation of foreign cultural elements, a vast number of translated texts serve as media, via which foreign ideas and concepts are introduced into the culture of the recipient nation. Importation of this kind implants heterogeneous elements into the target culture, enriches its development.

On the other hand, the target social and cultural system provides sources for the translator and has a certain impact on the literary translation. To make a better understanding, I shall present here a definition of culture. Although it is said that culture is defined in hundreds of ways, the term "culture" taken from culture-oriented translation scholars' idea is proper enough to be borrowed in this paper: A complex 'system of systems' composed of various subsystems such as literature, science, and technology. Within this general system, extra literary phenomena relate to literature not in a piecemeal fashion but as interplay among subsystems determined by the logic of the culture to which they belong. (Steiner, 1984:112)

Seen in this light, culture is no longer restricted to a narrow sense, but extends to a broader field, referring to all socially conditioned aspects of human life. Translation, literary translation is no exception, is one part of culture and no doubted affected and restrained by other factors of culture. As Lefevere remarks that any culture and society is the environment of a literary system and all systems are open to and interact with each other. (Lefevere, 1992: 14) Moreover, because these systems are rooted deeply in the target cultural context, the importance of the cultural context is made much account of. By "cultural context", we take it as "a world vision that links together the members of social group and distinguished them from others," or as "a set of cultural predispositions (conventions, beliefs, values and assumptions) internalized in the mind of the individual but socially determined". (Boase-Beise, 1999:61) So a translated work is always made in a certain socio-cultural background and the process of translating is a cultural bound activity. Literary translation is no exception, which is influenced not only by the source culture at one end but also the target culture at the other end.

\section{Cultural Constraints on Literary Translation}

Literary translation exerts great influence on the target culture, and at the same time, the target culture has never stopped restraining the process of literary translation. It is held that "there is always a context in which the translation takes place, always a history from which a text emerges and into which a text is transposed." (Lefervere: 1990:11) As a matter of fact, literary translation has never escape from the constraints of a certain target cultural context. Andre Lefevere made a detailed analysis of the sociological and cultural factors that govern the translation process in his book Translation, Rewriting and the Manipulation of Literary Fame. He claimed that two factors basically determine the translation process, that is, the ideology and the literary norm dominated in the target culture at the time a translation is made. And in the following paragraphs, the author is going to illustrate, with examples, how ideology, literary norms and other cultural factors condition literary translation.

The prevailing ideology of a target culture at a given time exerts more influence on the selection of the source materials in the translation activity. In the Abbasia Dynasty of Arab Empire the translation of Greek culture almost covered the 
entire science field, but excluded Greek literary works. For this phenomenon there were two reasons. The first involved religion. What Arabian Islam preaches is monotheism, i.e. in the universe Allah is the only force that controls and governs the destiny of mankind and the development of things. However, what the Greek literary works reveal is polytheism, which is out of tune with the Islam doctrines and was naturally excluded by Arabian rulers and translators. The second reason involved literature itself. As early as about one hundred and fifty years before the birth of Islam, poetry had been created in the Arabian Peninsula and had achieved considerable successes. Its representative work was a series of "suspending poems". The Abbasia Dynasty further developed Arabian poems. Arabs were always proud of their poems. Because of such a sense of nationalistic pride, they yielded a psychology of despising foreign literary works.

During the 1950s, class struggle was considered the all-important task of China, so class struggle was imposed as the primary norm for categorizing literary works during this period. "Generally speaking, only literary works from the Soviet Union and other socialist countries, as well as former colonies of European countries, were deemed to be qualified for translation."(Lin Kenan as qtd. by Tymoczko, Maria., and Gentzler, Edwin, 2002:180) Thus, there was strict control of textual selection during this period, a control exercised in accordance with the predominant political orientation. As for Western literary works, particularly American and English literature, only those depicting class struggle and racial discrimination - that is, only those exposing the dark side of capitalist society --- were deemed worthy of translation. Thus, for example, Uncle Tom's Cabin was selected for its delineation of racial oppression and Oliver Twist for its portrayal of capitalist exploitation. Many other masterpieces, James Joyce's Ulysses for one, were labeled as decadent and reactionary; they remained untranslated until the early 1990s when the norms of translation again changed in China.

The dominant literary norms at the time a particular translation is made also play a decisive part in the translation process. Lefevere investigated the nineteenth century's translations of Catullus' second poem and found that most of it rhymes even if the original does not. He explained, the need to rhyme was by no means from the "structure" of the original, on the contrary, it was imposed on translators by the literary norms of their day, which in the nineteenth century held that acceptable poetry translations should make use of the strategy of meter and rhyme (Lefevere, 1992:100).

Besides, whether the ruling class supports and whether its policy is lenient in the target culture are also important factors influencing translation activities. These also show the influence of political power in cultural field. Just as Susan Bassnet points out, studying translation today means "being aware of the processes that shape a culture at a given point of time". (Gentzler, 1993: 191) Such processes include extra literary factors: economy, politics, society, and so on.

\section{Conclusion}

From the examples, we can make a conclusion that cultural factors such as ideology and literary norms of the garget culture dictate the process of literary translation, just as Toury said that most texts were chosen to translate for ideological reasons (Gentzler, 1993:126). Besides, the dominant literary norms at the time a particular translation is made also play a decisive part in the translation process. Only by catering to the target culture and approving of it, can foreign cultures be accepted voluntarily by the target culture; otherwise, they are often rejected or resisted. Lefevere held such an opinion that on every level of the translation process, if linguistic considerations enter into conflict with consideration of an ideological and/or poetical nature, the latter consideration tends to win (Lefevere, 1990: 24). Therefore, it can be seen that that literary translating is a constrained activity influenced by other elements within the whole target culture. So cultural factors do restrain the selection of the original source and the translator's selection of translation strategy.

\section{References}

Boase-Beier, Jean and Michael Holman, ed. (1999). The Practice of Literary Translation: Constrains and Creativity. Manchester: St. Jerome Publishing.

Gentzler, Edwin. (1993). Contemporary Translation Theories. New York: Routledge.

Gu, Jun. (2001). Multi-culture Studies. Bei Jing: New World Pubishing.

Lefevere, Andre. (1990). Translation, History and Culture. New York: Routedge.

Lefevere, Andre. (1992). Translating, Rewriting and the Manipulation of Literary Fame. London: Routledge.

Schaffner, Christina, and Helen Kelly-Holmes, ed. (1995). Cultural Function of Translation. Clevedon: Multilingual Matters Ltd..

Steiner, Peter. (1984). Russian Formalism. Ithaca and London: Cornell University Press.

Xie, Tianzhen. (2003). New Perspective of Translation Studies. Qingdao: Qingdao Publishing House. 